\title{
Comparing CALIPSO and ground-based measurements of clouds at Camagüey
}

\section{Comparación de las mediciones de nubes realizadas desde CALIPSO y tierra sobre Camagüey}

\author{
J. Rosas, B. Barja \\ Atmospheric Optics Group of Camagüey, (GOAC) Camagüey Meteorological Center. \\ ${ }^{(*)}$ E-mail: jrosas@goac.cu \\ Received: 18/05/2015 Accepted: 06/11/2015 \\ DOI: $10.7149 /$ OPA.48.4.271
}

\begin{abstract}
:
The Cloud-Aerosol Lidar with Orthogonal Polarization (CALIOP) aboard Cloud-Aerosol Lidar and Infrared Pathfinder Satellite Observations (CALIPSO) satellite provides a new view of cloud properties data with higher spatial resolution than former satellites devices around the world, especially optically-thin clouds. Assessment of this useful data comparing with data from groundbased measurements is an opportunity for estimating uncertainties in clouds properties obtained from satellites. That is very important for increasing the knowledge about clouds and their representation in climate models. In this paper Cloud Optical Depth (COD) lower than 5 from level 2 version 3.01 cloud profile data of CALIPSO and AErosols RObotic NETwork (AERONET) groundbased sun photometer (SP) measurements were compared during the period since 2010 to 2014. Cloud frequency is computed as a ratio between cloud measurements and all possible measurements for each instrument. A collocated measurements comparison and general statistics comparison was conducted.
\end{abstract}

Key words: COD, CALIPSO, AERONET

\section{RESUMEN:}

El lidar Aerosol-Nube con Polarización Ortonormal (CALIOP, siglas en inglés) a bordo del Satélite Observaciones Exploratorias por Satélite de Nubes y Aerosoles en el Infrarrojo y mediante Lidar (CALIPSO, siglas en inglés) provee una nueva visión de los datos de propiedades de nubes con alta resolución espacial comparados con otros antiguos instrumentos satelitales alrededor del mundo, especialmente de las nubes ópticamente finas. La evaluación de estos útiles datos comparando con datos de mediciones en base a tierra es una oportunidad para estimar las incertidumbres en las propiedades de las nubes obtenidas desde mediciones satelitales. Esto es muy importante para incrementar el conocimiento acerca de las nubes y su representación en modelos climáticos. En este artículo se comparan los valores de mediciones de Espesor Óptico por Nubes (COD, siglas en inglés) por debajo de 5 de los datos de perfiles de nubes versión 3.01 nivel 2 de CALIPSO con las mediciones del fotómetro solar (SP, siglas en inglés) ubicado en tierra de La Red Robótica de Aerosoles (AERONET, siglas en inglés) durante el período del 2010 al 2014. Se calcula la frecuencia de nubes como la relación entre las mediciones de nubes y todas las posibles mediciones realizadas para cada instrumento. Fueron realizadas comparaciones de mediciones puntuales así como de estadísticas generales de ambos instrumentos.

Palabras clave: COD, CALIPSO, AERONET 


\section{REFERENCES AND LINKS / REFERENCIAS Y ENLACES}

[1] M. H. Zhang, W. Y. Lin, S. A. Klein, J. Bacmeister, S. Bony, R. T. Cederwall, A. Del Genio, J. J. Hack, N. Loeb, U. Lohmann, P. Minnis, I. Musat, R. Pincus, P. Stier, M. J. Suarez, M. J. Webb, J. Wu, S. C. Xie, M. Yao, J. H. Zhang, "Comparing clouds and their seasonal variations in 10 atmospheric general circulation models with satellite measurements," J. Geophys. Res. 110, D15S02 (2005). http://dx.doi.org/10.1029/2004JD005021

[2] C. S. Bretherton, P. N. Blossey, C. Stan, "Cloud feedbacks on greenhouse warming in the superparameterized climate model SP- CCSM4," J. Adv. Model. Earth Syst. 06 (2014). http://dx.doi.org/10.1002/2014MS000355

[3] G. Stephens, "Cloud feedbacks in the climate system: A critical review," J. Clim. 18, 237-273 (2005). http://dx.doi.org/10.1175/JCLI-3243

[4] T. Inque, M. Satoh, Y. Hagihara, H. Miura, J. Schmetz, "Comparison of high-level clouds represented in a global cloud system-resolving model with CALIPSO/CloudSat and geostationary satellite observations," J. Geophys. Res. 115, D00H22 (2010). http://dx.doi.org/10.1029/2009JD012371

[5] X. Dong, P. Minnis, B. Xi, S. Sun-Mack, Y. Chen, "Comparison of CERES-MODIS stratus cloud properties with ground- based measurements at the DOE ARM Southern Great Plains site," J. Geophys. Res., 113, D03204 (2008). http://dx.doi.org/10.1029/2007JD008438

[6] M. D. Winker, M. A. Vaughan, A. Omar, Y. Hu, K. A. Powell, Z. Liu, W. H. Hunt, S. A. Young, "Overview of the CALIPSO mission and CALIOP data processing algorithms", J. Atmos. Ocean. Technol. 26, 23102323 (2009). http://dx.doi.org/10.1175/2009JTECHA1281.1

[7] J. C. Chiu, C. Huang, A. Marshak, I. Slutsker, D. M. Giles, B. N. Holben, Y. Knyazikhin, W. J. Wiscombe. "Cloud optical depth retrievals from the Aerosol Robotic Network (AERONET) cloud mode observations," J. Geophys. Res. 115, D14202 (2010). http://dx.doi.org/10.1029/2009JD013121

[8] J.L. Guerrero-Rascado, M.J. Costa, A.M. Silva, F.J. Olmo, "Retrieval and variability analysis of optically thin cloud optical depths from a Cimel sun-photometer," Atmospheric Research 127, 210-220 (2013). http://dx.doi.org/10.1016/j.atmosres.2012.10.025.

[9] B.A. Baum, A.J. Heymsfield, P. Yang, S.T. Bedka, "Bulk scattering models for the remote sensing of ice clouds. Part 1: Microphysical data and models," J. Appl. Meteorol. 44, 1885-1895 (2005). http://dx.doi.org/10.1175/JAM2308.1

[10] T. J. Thorsen, Q. Fu, J. M. Comstock, C. Sivaraman, M. A. Vaughan, D. M. Winker, D. D. Turner, "Macrophysical properties of tropical cirrus clouds from the CALIPSO satellite and from groundbased micropulse and Raman lidars," J. Geophys. Res. Atmos. 118, 9209-9220 (2013). http://dx.doi.org/10.1002/igrd.50691

[11] S. T. Massie, J. Gille, C. Craig, R. Khosravi, J. Barnett, W. Read, D. Winker, "HIRDLS and CALIPSO observations of tropical cirrus," J. Geophys. Res. 115, D00H11 (2010). http://dx.doi.org/10.1029/2009JD012100

[12] Giovanni-The Bridge between data and science site (Giovanni-3). Consulted in July 1, 2015. http://gdata1.sci.gsfc.nasa.gov/daac-bin/G3/gui.cgi?instance_id=MODIS_MONTHLY_L3

\section{Introduction}

Cloud systems are an important issue for numerical climate and weather forecast models. Despite of clouds importance, their parameterization in the models and characteristics are not well represented in depth [1]. The scarcity of high-resolution data and measurements under different climate regimes contribute to these constraints.

Clouds feedbacks on climate change is still uncertain using coupled atmosphere-ocean general circulation models partially due to the need for complex parameterizations of clouds [2]. Nowadays with the inclusion of active sensor as radar and lidar on board satellites, these techniques become powerful tools for studying clouds profiles and clouds effects on Earth radiation budget.

Lidar is very sensitive to optically-thin clouds, which are very important in modulating the Climate System [2]. Cirrus clouds constitute an example of them. However they play a different role than other high 
clouds. Due to they are placed at higher altitudes and they are the optically thinnest clouds They warm the atmosphere more effectively [3]. Therefore an appropriate representation of cirrus clouds is one of the most important topics for improving climate models [4].

The Cloud-Aerosol Lidar and Infrared Pathfinder Satellite Observations (CALIPSO) mission flies in formation with A-train satellite's constellation. Cloud-Aerosol Lidar with Orthogonal Polarization (CALIOP) aboard on it constitutes the highest advanced in the remote sensing of atmosphere especially in optically-thin clouds, which were difficult to detect formerly.

Ground-based measurements are an opportunity for validating and estimating uncertainties in clouds properties obtained from satellites. Consequently, comparison between satellite and ground-based measurements must be carried out carefully. Because of the spatial and temporal sampling differences between these two types of observations, collocated measurements are needed between both instruments due to the variability of cloudiness [5].

In this paper Cloud Optical Depth (COD) values from CALIOP clouds products and the Aerosol Robotic Network (AERONET) are compared at Camagüey, Cuba.

The following section "dataset and methods", explains characteristics of CALIPSO and AERONET sunphotometer datasets and the procedures used for the comparison. We also explain a technique to combine the AERONET COD and visual observation to pair the COD with cloud type. The method to compute COD from sun-photometer using data eliminated by the cloud-screening algorithm is also shown. The next section displays the results of the comparison and discusses the findings. Finally, the conclusions of the analysis are given.

\section{Datasets and Methods}

\section{2.a. CALIOP datasets.}

Aboard CALIPSO, CALIOP operates continuously producing simultaneous co-aligned pulses at $1064 \mathrm{~nm}$ and $532 \mathrm{~nm}$ during day and night. The laser pulse repetition frequency of $20.16 \mathrm{~Hz}$ produces footprints every $335 \mathrm{~m}$ along the track over ground. The footprints of CALIOP are located on the ground track of CALIPSO, because it flies in a near nadir altitude. CALIPSO provides a near global coverage $\left(82^{\circ} \mathrm{N}-82^{\circ} \mathrm{S}\right)$ and it is a $705 \mathrm{~km}$ sun-synchronous polar orbit with repeating cycle of 16 days crossing the equator about 13:30 local solar time.

Cloud-related products of CALIOP level 2 version 3.01 data are in two files types: cloud layer and cloud profile. Cloud profile files are used to evaluate the cloud frequency in the present work. This product includes as primary parameters $532 \mathrm{~nm}$ backscatter and extinction. They have $20 \mathrm{~km}$ of maximum altitude and $60 \mathrm{~m}$ of vertical resolution. The horizontal resolution for cloud profile is $5 \mathrm{~km} \mathrm{[6].} \mathrm{The} \mathrm{cloud}$ optical depths are obtained by integrating the $532 \mathrm{~nm}$ cloud extinction profile, reported in this product. Because of the attenuation of the laser in the clouds, COD from CALIOP are below 5 .

CALIPSO passes over Camagüey region around 7 GMT and 18 GMT with time intervals of about 6, 10 and 16 days. However, because of CALIPSO track never reaches Camagüey Meteorological Center experimental site, then is not possible to obtain simultaneous measurements. Thus, we consider distances from the experimental site to obtain collocated measurements in a circle with $20 \mathrm{~km}$ of radius. In the case of general mean statistics comparisons, a circle with radius of $100 \mathrm{~km}$ is considered. The chosen spatial domain is appropriated to this study because of thin cirrus clouds has relatively low spatial and temporal variability with large horizontal scales typically around $100 \mathrm{~km}$, compared with other cloud types $[10,11]$. The time period of CALIOP dataset employed in this work spans from June 2010 until August 2014, in order to conduct a comparison by the availability of the AERONET photometer dataset. The quality control in order to select a suitable value for COD is made using the cloud-aerosol discrimination (CAD) score and Extinction QC Flag_532 parameters from Cloud Profile Dataset.

Cloud frequency for the survey region was computed as a ratio of total cases where the cloud type is observed in the column and total column measurements.

\section{2.b. Sun-Photometer (SP) located at Camagüey Meteorological Center, Cloud Mode (CM).}

The AERONET is a ground-based sun-photometer network that is designed to derive atmospheric particle optical and microphysical properties. The sun-photometers are instruments pointing to the sun and sky 
with a $1.2^{\circ}$ full field-of-view. These instruments measure the radiance at selected wavelengths from 440 to $1020 \mathrm{~nm}$ during the daytime. Aerosol Optical Depth (AOD) is determined using direct sun measurements. The direct sun measurements are composed by three simple measurements called triplet. The variation of the radiance in this triplet is used as a criterion for screening out clouds contamination in the aerosols measurements. Thus, the AOD dataset have three quality levels the level "1.0" with the raw data, the level "1.5" contain the measurements with cloud contamination screened and the level "2.0" have measurements with the pos-calibration correction applied. When the sun-photometer is not able to make aerosol measurements because of the clouds blocking the sun, a cloud measurement is conducted (Cloud Mode (CM)). In this stage the instrument point to the zenith to make irradiances measurements. It is possible to retrieve COD values from these irradiances measurements [7] and included in the AERONET dataset used in this paper. There is also the possibility to calculate COD from the cloud "contaminated" measurements of AOD discarded by the application of the cloud screening procedure. This method is explained in the next subsection.

The experimental site is located in Camagüey Meteorological Center $\left[21.42^{\circ} \mathrm{N},-77.85^{\circ} \mathrm{W}\right.$ ). In this site a Cimel sun-photometer belonging to the Iberian network for aerosol measurements (RIMA, in Spanish) was installed in 2008 as part of AERONET. The sun-photometer cloud measurements began in June 2010 at the site. The AERONET data used for this investigation spans from June 2010 up to August 2014.

Furthermore, at the experimental site manually actinometrical observations are made using a Yanichevsky actinometrical station (currently working) manufactured at the former Soviet Union. In this station hourly solar irradiances measurements from sunrise up to sunset are conducted. Visual observations of clouds are reported as complementary observations. The variables reported in visual observations are cloud type, low cloud coverage ( $\mathrm{NbB}$ ), and total cloud coverage (the two last variables in tenth parts of the sky). Cloud type at zenith began to be reported in visual observations, since March 15, 2011, following the installation of sun-photometer.

A combination between AERONET COD and actinometrical visual cloud observations (Correspondence Criterion) is set up for finding COD associated with cloud types, in order to compare with clouds types COD from CALIOP. Cloud frequency from Cimel sun-photometer dataset is computed as a ratio between the sum of all cloud mode measurements and the direct sun measurements not reaching the AOD level 1.5 (differences between 1.5 and 1.0 of AOD level), and all direct sun measurements.

\section{2.c. Method of Computing COD using data eliminated by the cloud-screening algorithm (ECSA).}

The method of retrieving COD for optically thin clouds is made by using data eliminated by the cloudscreening algorithm (ECSA) that are not useful for computing AOD [8]. For this purpose AOD level 1.0 data that did not became as 1.5 level $\left(A O D_{1.0}^{\text {discarded }}(\lambda)\right)$ is employed. These values contain the contribution of the aerosols and thin clouds; because of the Cloud Mode is not accomplished. Then it is able to calculated the apparent COD (COD apparent) using an AOD interpolated from the closets AOD value just before and after the cloudy measurement as [8] explain. These $A O D_{1.0}^{\text {discarded }}(\lambda)$ were corrected also for the post calibration process of the sun-photometer. The final COD is computed from equation 1 when $K_{F S C}$ is the forward scattering correction factor based on the knowledge of the phase function for angles lower than half field-of-view. The set of the $K_{F S C}$ factor employed in the present paper was the same one computed by [8] from the bulk scattering model [9]. This model is based on reanalysis of in-situ data from a variety of middle-latitude and tropical ice cloud field experiments. These correction factors relatively vary with the effectives radius of clouds. Then it is important to have a priori knowledge of cloud particle effective radius [8]. We use monthly mean effective radius datasets calculated using the MODIS Terra and Aqua daily level 3 data version 5.1 , with $1^{\circ} \times 1^{\circ}$ grid of resolution from Giovanni web site [12]. The uncertainty of the method is explained in [8], there are two sources contributing to the uncertainty of COD value: the determination of $C O D^{\text {apparent }}$ and $K_{F S C}$. Therefore in the worst case for subvisual cirrus the relative uncertainty may have values near $60 \%$. This is a high relative uncertainty, but we are taking in account these values of COD trying to increase the number of cases in the comparison between COD obtained by two different measurements source. We will take the COD in $440 \mathrm{~nm}$ for this work.

$$
\begin{gathered}
C O D(\lambda)=K_{F S C} C O D^{\text {apparent }} \\
\operatorname{COD}^{\text {apparent }}(\lambda)=A O D_{1.0}^{\text {discarded }}(\lambda)-A O D_{1.5}^{\text {interpolated }}(\lambda)
\end{gathered}
$$




\section{2.d. Correspondence Criterion between sun-photometer measurements and visual observations.}

In order to associate the COD from sun photometer to a cloud type, we introduce a Correspondence Criterion between sun-photometer COD and visual observations of cloud type from actinometrical observations. With this procedure we could compare COD of different types of clouds from the both datasets. Then, only middle and high clouds from the visual observations are considered due to particularity of the cloud types measured by CALIPSO and reported in the cloud product files.

The procedure of Correspondence Criterion to associate COD for middle or high clouds is made by 4 different ways based in the conditions of cloud mode of AERONET, and characteristics of visual datasets: three conditions for COD obtained from CM and one for COD from ECSA.

For the case of COD from CM the 3 different conditions of Correspondence Criterion are:

1. Condition of NbB below 3/10. zenith(zenith angle 0 ) Then, the coincident COD measurements are selected in the time interval of 10 minutes before and after the beginning time of actinometrical observations.

2. Search of middle or high clouds types reported at zenith with $\mathrm{NbB}$ below 5/10 in actinometrical observation. In this case the coincident minutes ranges of AERONET with actinometrical observation was limited to the time of actinometrical observations (12-24 minutes od each hour) without hours range is not a condition

3. COD is selected when the AERONET CM COD measurement (out of the \pm 10 minutes interval of each actinometrical observation) is between two contiguous actinometrical observations with the same middle and high cloud type presence and $\mathrm{NbB}$ under $3 / 10$ in these two contiguous actinometrical observations.

In the case of COD from ECSA the correspondence Criterion has the next conditions:

1. COD the actinometrical observation with middle or high clouds types reported at zenith with $\mathrm{NbB}$ below $3 / 10$ is searched. In this case there is not hours range. Coincident minutes ranges was setup in the time interval of 10 minutes before and after the beginning time of actinometrical observations. If the AERONET ECSA COD measurement time is between two contiguous actinometrical observations with the same conditions of middle or high clouds, the ECSA COD is taken.

\section{2.e. Comparison Criterion.}

In order to obtain a collocated measurement of the CALIOP with the Camagüey sun-photometer, CALIOP COD values falling within $20 \mathrm{~km}$ of maximal distance to the experimental site are taken. Because of all the measurements of CALIOP falling within $20 \mathrm{~km}$ were made at $7 \mathrm{GMT}$, contrasting AERONET measurements begin about 12 GMT and finish around 00 GMT in dependence of the season, we look up measurements of long-lifetime clouds. The temporal permanence of the thin cirrus clouds measured by CALIOP is high, sometimes this type of clouds are present during all the night. Therefore visual observations of clouds from surface were also used, to find out presence of cirrus during the day before CALIPSO measurement and in the beginning of the daytime of CALIPSO measurements. Then AERONET COD value under 5 in the day before or in the day of CALIOP measurement was selected for these coincident criteria. CALIOP measurements made under coincident criterion were averaged.

Also a statistical comparison is made between both datasets taking CALIOP measurements falling within $100 \mathrm{~km}$ of maximal distance to the experimental site. The thin cirrus clouds have relatively low spatial and temporal variability with large horizontal scales typically around $100 \mathrm{~km}$ as we explain previously and other studies using similar or higher spatial window $[10,11]$. This comparison is made between the overall data and clouds types. Monthly statistical comparison is evaluated by making a linear regression between relative frequencies of both monthly COD distributions, of CALIOP and Sun-photometer. Annual cycle of mean values and cloud frequency between both datasets is also assessed.

Figure 1 shows the survey region covering the Camagüey Province in Cuba. The cross shows the position of the experimental site where CIMEL sun-photometer is located. The small circle with $20 \mathrm{~km}$ of radio is a region for selecting collocated CALIOP measurements. The external circle with radio of $100 \mathrm{~km}$ centred at the site is selected to obtain CALIOP measurements for statistical comparison with sun-photometer measurements. 


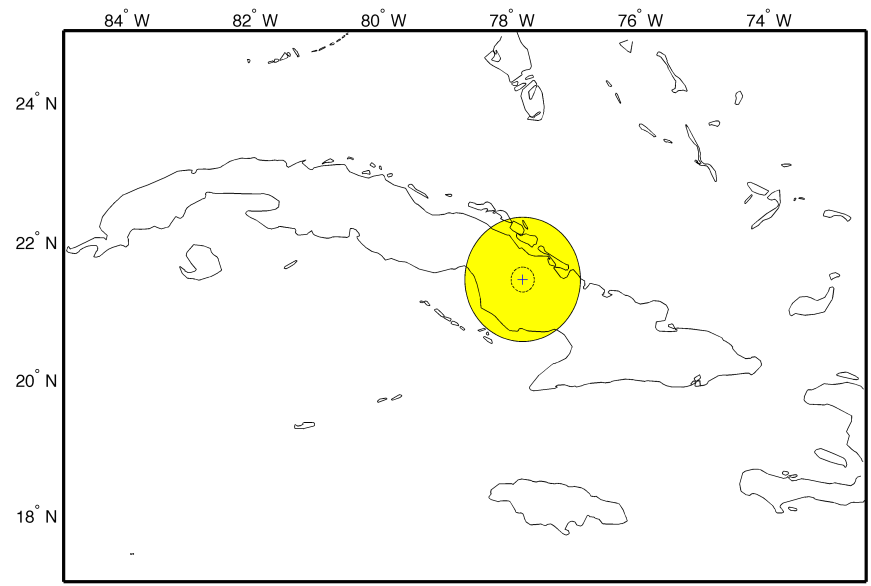

Fig.1. Survey region for comparison between both datasets, cruise shows the position of the experimental site where sun photometer is installed. Small Circle represents radio of $20 \mathrm{~km}$ respect to sun photometer location, external circle represent $100 \mathrm{~km}$ around sun photometer location

\section{Results}

\section{3.a. Collocated measurement comparison.}

The collocated comparison values are shown in the Table 1, COD values and uncertainties are also introduced. Two COD coincident measurements for CM COD and CALIOP were obtained. First one in April 4, 2011 shows COD for AERONET (CALIOP) of 0.35 (0.12). The second one in August 26, 2011 has COD values of $0.46(0.10)$. Both collocated measurements show higher COD values for AERONET. For ECSA COD and CALIOP comparison, 3 collocated measurements were found. It can be seen the opposite of the previous cases, with COD values of CALIOP higher than AERONET. However in the case of June 9, 2012 both measurements almost agree. Differences between COD values for coincident of CM and CALIOP are 0.23 and 0.36 . For the ECSA collocated comparison differences are between 0.55 and 0.02 for the last case of June 9, 2012.

Table 1. Collocated COD measurements comparison between CALIOP and sun-photometer (CM and ECSA)

\begin{tabular}{|l|c|c|c|c|c|c|c|c|}
\hline \hline & \multicolumn{4}{|l}{ CALIOP } & \multicolumn{4}{l|}{ Sun-Photometer } \\
\cline { 2 - 10 } & Date & Hour & COD & Uncer & Date & Hour & COD & Uncert \\
\hline \hline \multirow{2}{*}{$\begin{array}{l}\text { Cloud Mode } \\
\text { (CM) }\end{array}$} & $2011-04-04$ & 7 & 0.12 & 0.050 & $2011-04-03$ & 14 & 0.35 & 0.0014 \\
\cline { 2 - 10 } & $2011-08-26$ & 7 & 0.10 & 0.042 & $2011-08-26$ & 14 & 0.46 & 0.0968 \\
\hline \multirow{5}{*}{ ECSA } & $2010-07-06$ & 7 & 0.73 & 0.296 & $2010-07-06$ & 15 & 0.18 & 0.0200 \\
\cline { 2 - 9 } & $2012-04-06$ & 7 & 0.34 & 0.139 & $2012-04-06$ & 12 & 0.02 & 0.0141 \\
\cline { 2 - 9 } & $2012-06-09$ & 7 & 0.04 & 0.017 & $2012-06-09$ & 11 & 0.02 & 0.0180 \\
\hline \hline
\end{tabular}

\section{3.b. General Statistics Comparison.}

The statistical analysis of both data series subsets from June 2010 to August 2014 inside the survey region (100 km circle) gives us a general view of comparison. Figure 2 shows the COD frequency distributions for CALIOP (Figure 2a) for values below 5, using 0.1 COD bins steps. The COD distribution from Cloud Mode (Figure 2b), from ECSA (Figure 2c), and all values of sun-photometer (Figure 2d) are also shown. For CALIOP, 1989 cases were analyzed. On the other hand, 1408 cases from the Cloud Mode AERONET were chosen. For ECSA 6069 cases were found out. Then for sun-photometer a total of 7477 cases are used.

Distributions of CALIOP and COD from Cloud Mode (CM) are almost agreed; however there are differences especially in the intervals centered at 0.1 and 0.2 of COD values. CM has the maximum placed at 0.2 with $20.6 \%$ and CALIOP has only $9 \%$ in the same COD interval. The interval centered in 0.1 is different to the COD distributions: CALIOP COD has their maximum frequency of $32.1 \%$, CM COD has only $5 \%$ and ECSA COD distribution has also maximum frequency with $76.7 \%$. For overall COD values of sun-photometer (SP), the distribution looks like to CALIOP where the maximum is placed at 0.1 (62.8\%). However the difference in this bin is still remarkable.

Nearly $67 \%$ and $91 \%$ of the COD values are below 1 for CALIOP and SP COD, respectively. It is important to note the increase of the relative frequencies of COD values above 2.5 for CALIOP. This behavior is not 
observed for the SP COD distribution. COD mean values are 0.3, 1.03 and 0.9 for SP, CM and CALIOP, respectively. CALIOP is more sensitive at CODs centered at 0.1 than $\mathrm{CM}$ of sun-photometer. However in this bin step ECSA of SP is more sensitive than CALIOP. A T-student hypothesis test shows significant statistical differences at $5 \%$ of statistical level, between CALIOP and each SP COD dataset.
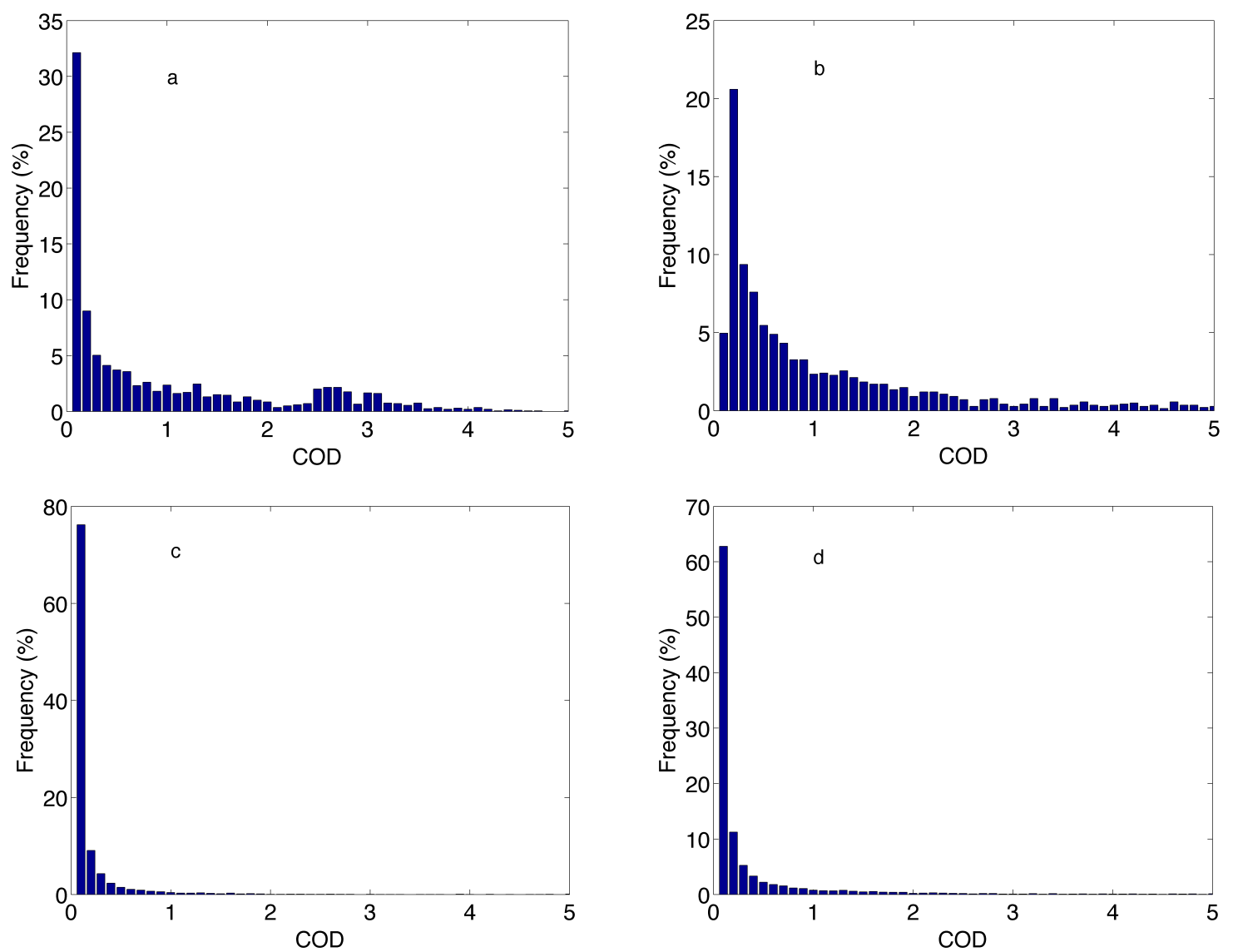

Fig. 2. COD frequency distribution for CALIPSO (a), sun-photometer Cloud Mode (b), Sun-photometer ECSA (c) and Sun-photometer $(\mathrm{ECSA}+\mathrm{CM})(\mathrm{d})$.

A general comparison between cloud types COD distribution between both datasets is also discussed below. As previously mentioned, only high and middle cloud types are considered for a comparison between both datasets. After the application of the correspondence criterion to identifying the matching cloud types with COD CM data, only cirrus clouds (Ci (8 cases)) and altocumulus (Ac (6 cases)) clouds types were found out. In the case of COD ECSA data 994 values were identify as Ci and only 22 as Ac. Regarding CALIOP, cases of COD belong to cirrus (Ci) [altocumulus (Ac)] are 1087 [29]. The original names for this cloud types from CALIOP cloud classification scheme are transparent Cirrus (Ci $\mathrm{i}_{\mathrm{t}}$ ) [transparent altocumulus $\left(\mathrm{Ac}_{\mathrm{t}}\right)$ ], but we eliminate transparent word in order to uniformity.

Figure 3 shows COD distribution of sun-photometer (CM and ECSA) and CALIOP for Ci and Ac cloud types. The maximums frequencies are placed in the COD interval centered at 0.1 for both cloud types. In this interval SP has $75 \%$ higher than CALIOP (50\%) for the Ci cloud type. Besides SP [CALIOP] has $97 \%$ [92\%] of the COD values below 1 . A test-student statistical test confirms the later, showing significance statistical differences at $95 \%$ for Ci. Concerning Ac, the amount of cases is lesser than cloud type Ci. The maximum is placed in the interval centered at 0.1 as well. At 0.1 is notable where SP [CALIOP] has $67 \%$ [41.4\%]. All values of CALIOP COD are below 1, however almost all SP COD fall in this range with $92 \%$ of the cases. 

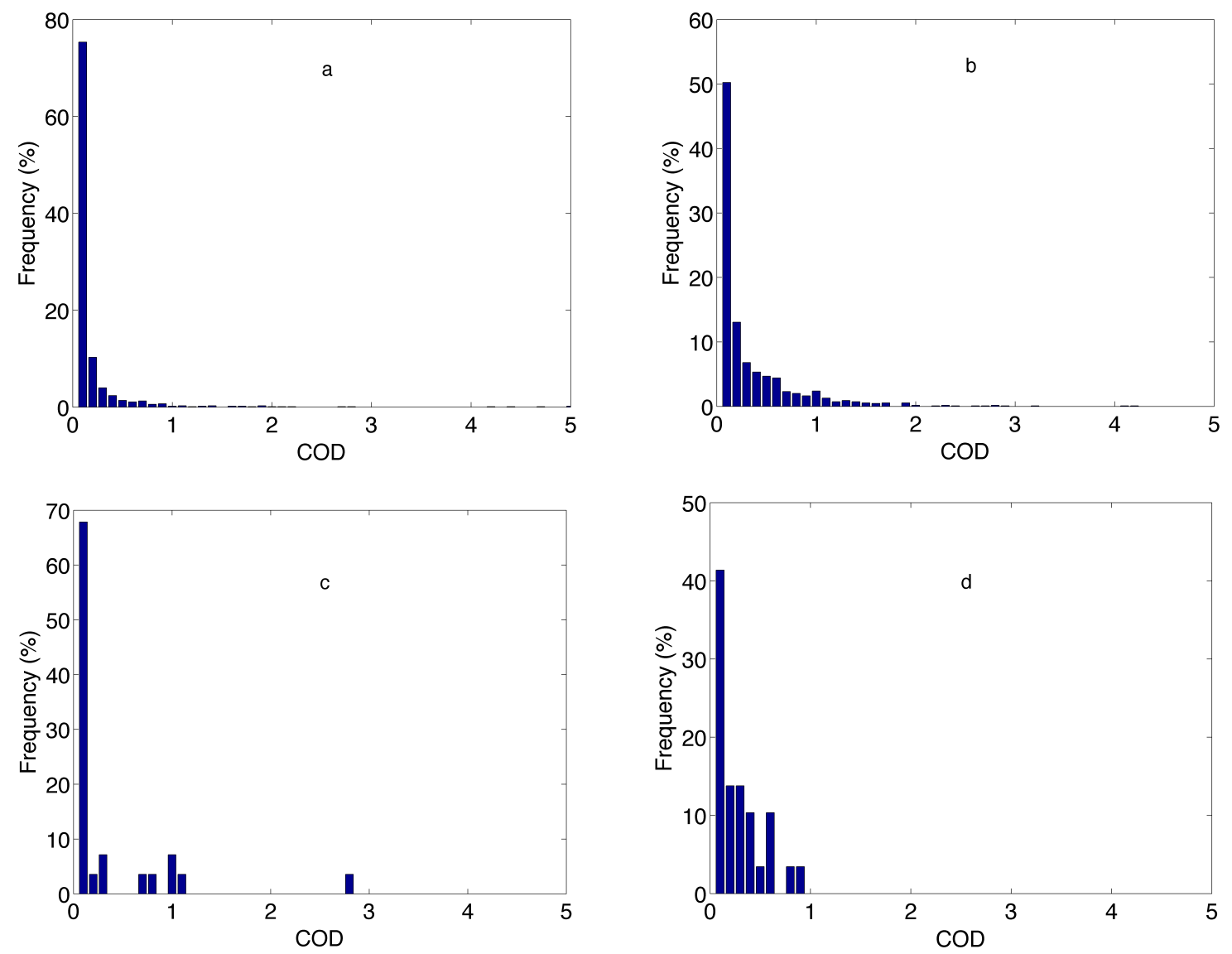

Fig. 3. COD distribution of Ci cloud type from SP (a) and CALIOP (b); and for Ac cloud type from SP (c) and CALIOP (d).

Monthly statistical comparison is also assessed through a linear regression between relative frequencies of both monthly COD distributions of all SP CODs (CM COD and ECSA COD) and CALIOP. Determination coefficients $\left(\mathrm{R}^{2}\right)$, slope $(\mathrm{m})$ and y axis intersect $(\mathrm{n})$ of linear relationship between CALIOP and AERONET are shown in Table 2.

COD datasets have not good match, but from May to September the relationship between both datasets becomes better with higher values of $\mathrm{R}^{2}$. Specially June, July and September have the lowest total mean percent differences below 1.3. These months belong to the rainy season in Cuba, where cirrus clouds occurrence increases. In July both datasets almost agree completely with the slope 0.86 and correlation coefficient of 0.97 .

CALIOP and sun-photometer scan the atmosphere from opposite point of view, and different geometry. This allows CALIOP detects very well high clouds types; also CALIOP is little sensitive to lows clouds. Whereas the sun-photometer at ground-base has the atmosphere aloft, then for detecting high clouds, there must be neither extended lows clouds nor middle clouds in the sun-path or at zenith. There are time period along the year where cloud behavior pattern favors it or is unfavorable to the best agreement. In the months from November to April stratocumulus clouds pattern are likely to develop due to of outbreak of cold air mass from North American Continent. Besides high clouds decrease as well, producing CALIOP likely measures lower clouds. At rainy season from May to October higher clouds occurrence increases as well as low clouds and middle clouds because of to the deep convection. Therefore CALIOP detects more frequently higher clouds than in the little rainy season. Besides, in this season low cloudiness decreases at early hour in the daytime letting sun-photometer detects higher clouds. In July the rain decreases due to the summer drought but the higher clouds not decrease in the same dimension, however the decreasing of lows clouds is compared to the little rainy season. Besides in July the cloud amount average of stratocumulus in the daytime is the lowest of the year. Moreover, in July the daytime cloudiness of middle clouds is the lowest of the rainy season. This allows better measurements of high clouds using sunphotometer and so, the best agreement of both datasets in this month. 
From October to April the relationship becomes weak, in these months the presence of low stratus and stratus cumulus increase notably, especially from December to Mars. Then this could be a 'handicap', increasing the differences between both datasets, because CALIOP is not sensible to measure low clouds. In February the highest differences between this datasets is found out with the lowest $\mathrm{m}(0.25)$ and highest $n$ (1.49), having the worst $\mathrm{R}^{2}(0.40)$. Thought, February has the lowest amount of COD values from CALIOP with only 22 cases.

It is also important to note, all months of the year have significant statistical differences at $5 \%$ significance level between both datasets. The maximum frequency for both datasets along the year is placed at the interval centered at 0.1 of COD. At interval centered in 0.1 of SP COD, frequencies are higher than CALIOP. However at 0.2 only in April and December frequency is higher for CALIOP.

TABLE 2. Monthly general comparison between both datasets, in red color the best agreement is shown.

\begin{tabular}{|c|c|c|c|c|c|c|c|c|c|c|c|c|c|}
\hline \multicolumn{2}{|l|}{ Month } & 1 & 2 & 3 & 4 & 5 & 6 & 7 & 8 & 9 & 10 & 11 & 12 \\
\hline \multirow{3}{*}{$\begin{array}{c}\text { Lineal } \\
\text { Regression }\end{array}$} & m (slope) & 0.54 & 0.25 & 0.40 & 0.28 & 0.66 & 0.71 & 0.86 & 0.42 & 0.51 & 0.36 & 0.50 & 0.42 \\
\hline & n (inter) & 0.92 & 1.49 & 1.19 & 1.44 & 0.67 & 0.57 & 0.27 & 1.15 & 0.98 & 1.26 & 0.99 & 1.15 \\
\hline & $\mathrm{R}^{2}$ & 0.84 & 0.40 & 0.85 & 0.48 & 0.90 & 0.98 & 0.97 & 0.94 & 0.92 & 0.81 & 0.86 & 079 \\
\hline \multirow{2}{*}{$\begin{array}{l}\text { Interval } \\
\text { maximum } \\
\text { frequency }\end{array}$} & SP & 0.1 & 0.1 & 0.1 & 0.1 & 0.1 & 0.1 & 0.1 & 0.1 & 0.1 & 0.1 & 0.1 & 0.1 \\
\hline & CALIPSO & 0.1 & 0.1 & 0.1 & 0.2 & 0.1 & 0.1 & 0.1 & 0.1 & 0.1 & 0.1 & 0.1 & 0.1 \\
\hline \multirow{3}{*}{$\begin{array}{l}\text { Mean } \\
\text { differences of } \\
\text { COD } \\
\text { distribution }\end{array}$} & At 0.1 & 28.1 & 50.4 & 41.2 & 48.8 & 19.5 & 14.1 & 6.1 & 36.8 & 29.7 & 37.3 & 29.6 & 38.7 \\
\hline & At 0.2 & 4.2 & 5.6 & 4.4 & -6.1 & 13.8 & 6.3 & 1.5 & 2.4 & 0.7 & 3.7 & 2.3 & -1.0 \\
\hline & Total & 1.6 & 2.6 & 2.0 & 2.0 & 1.5 & 1.1 & 0.9 & 1.7 & 1.3 & 1.8 & 1.6 & 2.1 \\
\hline \multicolumn{2}{|c|}{ Test-student hip at $5 \%$} & 1 & 1 & 1 & 1 & 1 & 1 & 1 & 1 & 1 & 1 & 1 & 1 \\
\hline \multicolumn{2}{|l|}{ CALIPSO cases } & 69 & 22 & 86 & 162 & 76 & 303 & 292 & 326 & 208 & 247 & 134 & 64 \\
\hline \multicolumn{2}{|l|}{ SP cases } & 690 & 612 & 655 & 711 & 574 & 527 & 481 & 652 & 548 & 739 & 673 & 615 \\
\hline
\end{tabular}

Annual cycle of the mean values of COD is shown in the Figure 4. There are some differences, as was also mentioned before, showed in the mean values analysis. Both datasets do not clearly show a seasonal behavior, maximum values for SP (CALIOP) are placed at November (December) with 0.46 (1.49). Opposite, the minimum mean values are placed at the same month in May with 0.24 (0.68). There also differences between mean COD from CM and ECSA with higher values for CM. The higher differences between mean values of SP COD datasets and CALIOP are found out in February and December with values between 1.01 and 1.21. The lower differences in mean values are placed in November with 0.33 .

Cloud occurrence frequency was also computed using both datasets. In the case of SP was computed as a ratio between measurements where cloud was detected (COD plus difference between AOD 1.0 and 1.5) and all correct sun measurements made by sun-photometer (AOD level 1.0 plus COD). This cloud occurrence must be called as cloud occurrence frequency across sun path. Besides due to the conditions of measuring of sun-photometer also this cloud occurrence belong to no precipitable clouds.

From CALIOP datasets cloud occurrence frequency were computed as a ratio of number of measurements where a cloud was detected and all measurements made within the radio of $100 \mathrm{~km}$ around sun photometer site.

Monthly cloud frequency with COD below 5 is shown in the Figure 5 for both datasets. As it can be seen in CALIOP cloud frequency, there is seasonal behavior where the higher values are found out in months of the rainy season from June to October. The minimum frequency value for CALIOP is placed on February with 0.02 , the maximum in June with 0.27 , the decreasing in July due to the summer drought is also shown, after that, the frequency increase up to August (0.26), decreasing again at the end of the year.

For SP the seasonal behavior is smaller, but is also shown, with maxima from the June to October, from this dataset is also observed the decreasing of frequency from April to May, The maximum of SP does not agree with CALIOP, being in October with 0.41, the minimum is placed in May with 0.31 . The summer 
drought is also observed with the slope of decreasing from June to July agrees with CALIPSO data. In general annual cloud occurrence cycles agree between both datasets, showing the pattern of the cloudiness characterizing the region and seasonality, being stronger from CALIPSO data.

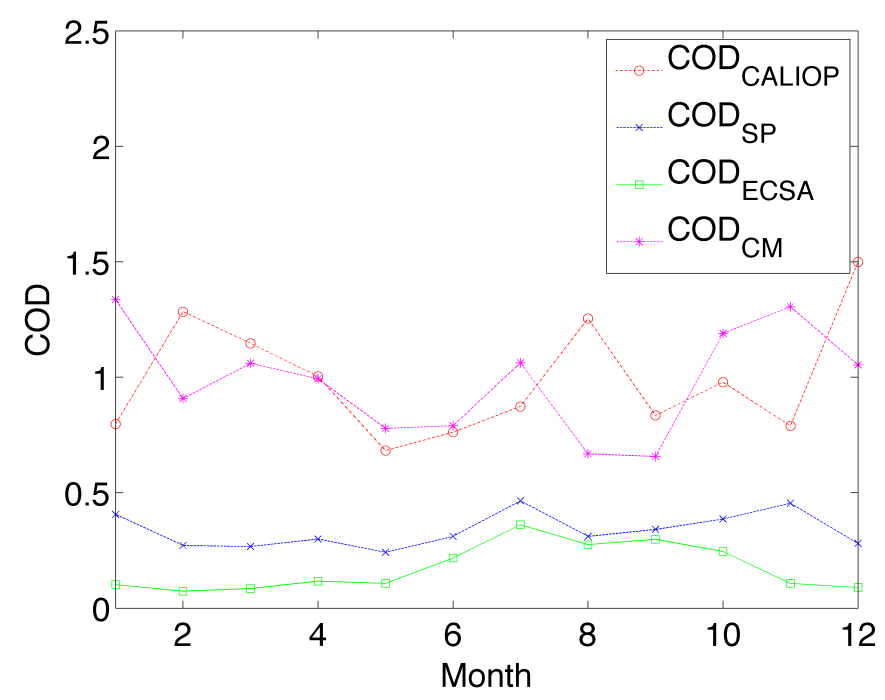

Fig. 4. Annual cycle of COD mean values for each dataset.

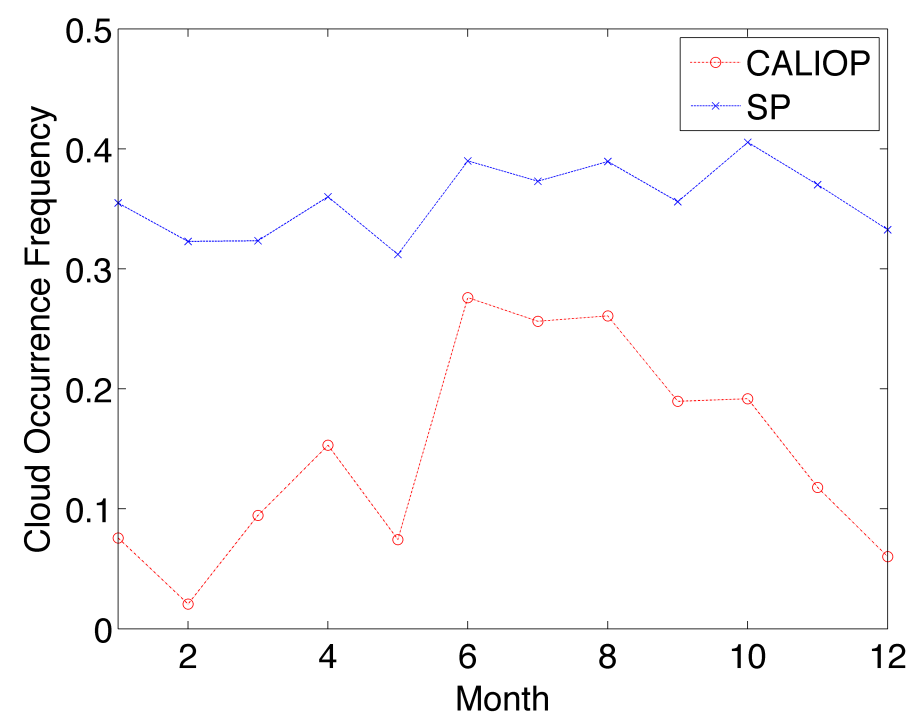

Fig. 5. Annual cycle of Cloud Frequency from each dataset.

\section{Conclusions}

A comparison of COD values and cloud frequency obtained from ground-based sun-photometer and CALIOP were carried out at Camagüey Cuba in the period time of 2010 to 2014. In order to do it two ways to compute COD from sun-photometer (Cloud Mode [CM] and data eliminated by the cloud-screening algorithm [ECSA]) are employed.

Collocated measurement comparison between sun-photometer COD and CALIOP COD datasets from 2010 to 2014 was conducted. Only 5 cases met the selection criteria. Higher values for COD were obtained from Cloud Mode (CM) than for CALIOP. In the case of COD obtained from data eliminated by the cloudscreening algorithm (ECSA) values are lower than CALIOP, having only one case with similar values of COD.

General comparison of COD distributions in the studied area shows differences especially in the interval of COD centered at 0.1 and 0.2 , with higher frequencies of ECSA in lower COD values and maximum located 
at 0.1. In general COD from sun-photometer (CM+ECSA) mean value with 0.3 is lower than from CALIOP with 0.9. Both COD datasets have significant statistical differences at $5 \%$. CALIOP is more sensitive for COD values nearby 0.1 than CM of sun-photometer. However in this interval of COD ECSA method of SP is more sensitive than CALIOP.

Monthly general comparison shows differences along the year. The relationship between both datasets becomes better from May to September, with the best agreement in July where conditions are likely to favor a clear measured of higher clouds.

There are also some differences between annual cycles of COD mean values. In general annual cloud occurrence frequency cycles agree between both datasets, showing the pattern of the cloudiness characterizing the region and seasonality. This seasonality is seen better in the CALIOP cloud frequency.

\section{Acknowledgements}

Authors want to thank to CALIPSO Search and Subsetting and GIOVANNI Wep Applications teams for provide the information about Clouds. Also to AERONET NASA our gratitude for including Camaguey site on the AERONET web site and provide the COD data. Also we express our gratitude to Dr. Juan Luis Guerrero Rascado for providing the forward scattering correction factors. 